\title{
Evaluation of practices in mental health care in the Brazilian Northeast
}

\section{Maria Aparecida Alves Sobreira Carvalho \& Verônica Morais Ximenes}

To cite this article: Maria Aparecida Alves Sobreira Carvalho \& Verônica Morais Ximenes (2016) Evaluation of practices in mental health care in the Brazilian Northeast, Journal of Prevention \& Intervention in the Community, 44:1, 40-50, DOI: 10.1080/10852352.2016.1102587

To link to this article: http://dx.doi.org/10.1080/10852352.2016.1102587

Published online: 23 Dec 2015.

Submit your article to this journal $₫$

Џ Article views: 1

Q View related articles $\square$

View Crossmark data ¿ 


\title{
Evaluation of practices in mental health care in the Brazilian Northeast
}

\author{
Maria Aparecida Alves Sobreira Carvalho ${ }^{a}$ and Verônica Morais Ximenes ${ }^{b}$ \\ ${ }^{a}$ Federal Institute of Education, Science and Technology, Sousa, Paraíba, Brazil; bepartment of \\ Psychology, Federal University of Ceará (UFC), Fortaleza, Ceará, Brazil
}

\begin{abstract}
This study presents a qualitative evaluation of mental health services, having as a goal to understand in what measure the care practices of a community mental health service in Fortaleza, Ceará (Brazil), have an impact in the strengthening of people diagnosed with mental disorders. Interviews were made mediated by selfphotography, a focus group, and in-depth interviews, organizing the contents in categories obtained by the critical hermeneutics method. The results indicate that those care practices promote strengthening processes, because care is not limited in its activities, and is respectful of the existential territory supporting the expressions of pain, of discontent, of the possibility of being and, wishing for different things, and are distanced from the ideology of submission and resignation.
\end{abstract}

\section{KEYWORDS}

Care; Community Psychology; mental health; strengthening

\section{Introduction}

There is a polysemous character in the concept of care reflected in many forms of production of mental health services, guided by concepts regarding illness, presenting diverse views and senses, with many ideological and political perspectives. In this article, we seek to understand the development of care in the Bom Jardim Community Mental Health Movement (Movement), a nongovernmental organization (NGO) in the Brazilian Northeast promoting actions that integrate mental health with art, culture, education, and professionalization, since 1996 in the Bom Jardim region located in the city of Fortaleza, State of Ceará. This is one of the most populous places in the city, facing problems such as lack of dwellings, employment, as well as safety, education, transport, and health. The neighborhood finds itself in a state of risk and social vulnerability.

The Movement is a community association that started working with leaders of the Bom Jardim neighborhood in 1996, who participated in the Basic Ecclesial Communities (BECs, also called Christian communities). They were Comboni missionaries who worked Catholic faith in its social dimension. In order to undertake the actions in the neighborhood, these leaders 
made several trainings to qualify its psychosocial activities to alleviate the suffering of people, who were not attended by the public health policies.

We inquired in what measure the care provided by Movement is capable of enabling the people's strength with a psychological history of suffering, overcoming a psychologizing and individualist vision of suffering, aiming at relations of welcoming, bonding, listening, and ethical-political commitment. Strengthening is:

the process in which members of a community develop together abilities and resources to control their life situation, acting in a committed, aware and critical manner, in order to reach a transformation of their surroundings according to their needs and aspirations, also transforming themselves in the process. (Montero, 2003, p. 72 , translated by the authors)

The concept of strengthening coming from the field of Community Psychology (Góis, 1993, 2008; Martin-Baró, 1998; Montero, 2003) provides bases to think about possibilities of collective production of mental health, recognizing the individuals' capacity to implicate themselves and modify their contexts, in a mental health policy integrated within the community, capable of producing real impact in the culture and in mental health attention's quality (Carvalho, Ximenes, \& Bosi, 2012). Therefore, there is a possibility of enabling mental health services in the evaluation of their care practices; the people's strengthening having an important aspect in the process.

Concerning care, in this aspect we are referring it to the concept of Bosi et al. (2011). That concept points to the emergent practices guided by a mental health network centered in a region able to produce a more humane care: less excluding, acknowledging the bio-psycho-socio-cultural determinants of illness, in subjects that keep themselves up-to-date with the world, creating and giving meanings. Concerning care allows the emerging of singularizing processes in a historical and culturally situated interaction net, capable of overcoming the asylum interdict when power for attributing sense was historically subtracted when the insane people had their civil rights disenfranchised, their speech was considered as not valid, since it "did not made sense," and their relations were threatened by exclusion.

\section{Method}

The critical perspective of hermeneutics (Bosi \& Mercado, 2007) from a Movement case study, was used as a data analysis technique. A focus group (FG), two interviews mediated by self-photography (SP), and an in-depth interview (I) were the means for data construction. The focus group had eight people that entered the Movement with mental disorder diagnosis and then, joined for volunteer actions facilitating and co-facilitating community therapy groups selfesteem, Math tutoring, massotherapy, and community garden groups. 
From people who moved from the role of user of services, to that of care provider, we selected eight subjects for the FG, choosing as criteria: having joined Movement as a user, with a mental disorder diagnosis; having participated in service activities for more than 1 year; and having participated in the coordination of some care activity. Two of the participants in the FG were selected for interview mediated by self-photography, since they had spoken very little during the FG and having a major and more complex diagnosis concerning social bonds such as hearing hallucinations, ideas of suicide, fear of interacting with others, and consequently social isolation.

The SP resource, according to Neiva-Silva (2003), was initially used to document the participant's perception, with minimal training, avoiding the usual disadvantages of verbal report techniques. That has the advantage of non-direction or induction from the researcher on the participant's look over a certain response category, the participant being the one selecting the stimuli.

In the SP mediated interview, we asked each person to take photos, using a camera given by the researcher, representing changes that happened in their lives since their participation in Movement. The use of SP in this research had as its purpose to provide access to another form of language not reducing to verbal expression, which is many times limited to make reference to subjective experiences, and to give time for the subjects to reflect over the changes occurring in their lives and to select the photos for the interview. Then, we did an in-depth interview with the Movement president, in order to understand the institution's history.

The spoken material was transcribed and organized into an interpretative net using the understanding provided by critical hermeneutics (Bosi \& Mercado, 2007). The names of the subjects in this article have been changed by the participants themselves, as well as the photos omitted in order to safeguard their privacy. The research respected ethical aspects, according to Resolution number 196/96 and was approved by the coordination of the researched service and by the Research Ethics Committee (COMPE) of the Federal University of Ceará (UFC), protocol number 103/10.

\section{Analysis and discussion of mental health care}

To understand the process of care carried out within Movement, we adopted four analytical categories: theoretical-conceptual, technical-assistencial, sociocultural, and biopolitical. The first three dimensions, theoretical-conceptual, technical-assistencial, sociocultural, are used by Amarante $(1994,2003)$ to indicate the foundations of the Brazilian Psychiatric Reform. He uses one more dimension, the legal-political one, which was analyzed by Carvalho, Ximenes, and Bosi (2012). We considered the Amarante (1994, 2003) model, as adequate for introducing the complexity of the care processes, not being only restricted to 
assistance technologies. The last dimension, biopolitical, came from the interpretation of spoken material, being incorporated to the discussion of the results. We remember that even though they are separately presented, each dimension is reciprocally connected and affected.

\section{Theoretical-conceptual dimension}

The theoretical-conceptual dimension, also known as epistemological, Amarante $(1994,2003)$ expresses the need to re-dimension the object of mental health by reconstructing new knowledge that may sustain new practices of care. Overcoming such dichotomy concepts produced by psychiatry as alienation/mental illness, therapeutic isolation, degeneration, normality/abnormality, therapeutics and cure.

In Movement the strategies of care are organized into five kinds: Therapeutic; Educational; Art, Music, and Spectacle; Professionalization; and Training. They are organized along various activities coordinated by volunteers or by Movement's workers. Margarida (FG) said that the enlargement of the activities brought problems to the gathering of resources, because the funders questioned, saying that: "what is the connection between this mental health movement and art and pre-university courses? So we explained that art, culture, work with children, the course all are part of mental health."

The structure of Movement's care practices go beyond the goal of the psychiatric symptom remission, so common in the asylum logic, acknowledging also the pains in other forms of exclusion generated by unemployment, violence, lack of perspective, and fear of new things. From the problems heard and lived by the community, new modes of interventions emerge:

All the initiatives that we built were a response to the needs that the people were bringing, so the first was self-esteem. We saw that people had internalized poverty, the fact that they didn't believe they could grow, so we started working with selfesteem groups. (Movement President, E.)

In order to understand the human being in the biological, psychological, social, and spiritual dimensions, Movement uses Martín-Baró's Liberation Psychology, Paulo Freire's Liberation Education, and Leonardo Boff's Liberation Theology (Movement President, E.). These theoretical sources provide bases for the discussion on Brazilian Psychiatric Reform for broadening the understanding of its object of study, which is mental health in its historical context.

\section{Technical-Assistencial dimension}

In this dimension, the new assistance model discussed, the possibility of strengthening a territorial network of attention to mental health, with features 
of interdisciplinarity and intersectoriality, developing a coordinated work in the promotion of many mental health actions, linking knowledge and action. To Mecca and Castro (2008), this service must be made of the choices of each subject, shared in a network of meetings, in a manner that enables the unexpected, the strange, to reach many diverse ways of being in the world.

The Movement's activities are not restricted to therapeutic approaches; they are directed to groups connected to art and spectacle, education and professionalization, having among them people from the community, members of the Movement's personnel, users of the Psychosocial Attention Center (Centro de Atenção Psicossocial [CAPS]) and people from other neighborhoods and institutions. The CAPS is an open mental health establishment, financed with public funds, that follows people with mental disorder diagnosis. There is a CAPS in the Bom Jardim neighborhood that functions in co-management between Movement and Fortaleza's City Hall, since 2005.

Mental health workers participating in care activities, interacting with other people with experiences of psychological suffering, reconfigures new relations of care by fostering a de-territorialization. To Franco, Merhy, Andrade, and Ferreira (2009), that is an opportunity to operate in the subjects' existential territories, which are found inside each one of them, organized by their subjectivity, in a difficult process, complex and painful, breaking away from the structured ways of work and production. The workers will find themselves in the world like it is, chaotic, but potent in its singularities. Along the possibility of emotional reconfiguration, it can also produce encounters of different social classes in that existential territory.

Care practices build circularity, where the care for themselves and the selfknowledge are used as experience for the implementation of new methods of dialogic and experiential character, when caring for others. There is an emphasis in self-esteem development in all training and professionalization activities to overcome the internalized poverty, where people show feelings of worthlessness and incapacity, acceptance of misery, and fear of new things. Jarbas (SP) states, "before I arrived in this group I didn't have many dreams. I didn't dream, for example, about having a family, I didn't even dream about finishing school and going to college." The feeling of incapacity made difficult the accomplishment of activities and the insertion in the job market:

I have always liked art, but I thought I was incapable and, when I started the organic card course, I went to class and dropped out, I didn't think I was capable. Later I came back and during the relaxation the organic card came to my mind, and I told myself I would do it when I got home. I made twenty cards to sell and I paid for the course I wanted to take. (Lotus Flower, FG)

According to Martín-Baró (1998), there is a fatalist attitude in the Latin American people facing their own existence and the relation a person 
establishes with their reality, expressed by attitudes of conformity and resignation before any circumstance, even the most negative ones. According to this author, fatalism constitutes a valuable ideological instrument for the dominant classes in which the ideologized acceptance of fatalism supposes a practical acceptance of the oppressing social order. That fatalism is overcome in care relations by way of meetings where the participants collectively discuss seeking for meaning in search for an existential totality allowing to give meaning and sense not only to health, but also to their own project of life (Ayres, 2004). For the subjects of this research, participation in care activities facilitated the strengthening by producing implications in each other's lives, and not only in a subjective well-being. Meetings promoted generated anguish and conflicts, but they also potentiated rediscoveries, sense of comprehension, overcoming stereotypes about themselves, about others, and about reality.

\section{Sociocultural dimension}

In the sociocultural dimension, there is a search for transformation of ways of living and feeling in people suffering, while at the same time their concrete situation of life begins to change. To Rotelli (2001), a mental health service that uses this perspective must have projects with the possibility of creating social places, ephemeral states, flexible spaces, by always learning with the need and singularity of others. This institution has survived beyond the wealth, due to a therapeutic practice of "artists, cultural men, poets, painters, men from the movies industry, journalists, life inventors, youths, work, parties, games, words, spaces, machines, resources, talents, plural subjects and the gathering of all this" (Rotelli, 2001, p. 98).

We state the necessity of discarding norms that regulate a care relation that favors personal dependence of people with illness experience, by enabling the reconstruction of their lives on legal and economic grounds, like indispensable spaces for their placement in the social exchange circuit, reestablishing their condition as members of the social body. So in care relation new power relations are redefined:

the situations of "crisis", no longer redirected to the inside of the subject who is its bearer, are reopened as crisis between the levels of power, between social interests, between institutions and institutional levels, requiring-on the technician's parta radically new mediation. (Basaglia, 2005, p. 249)

Social exchange space is widely lived in Movement, where the transition from the role of user to facilitator of care activity takes place through volunteer work, in which the potential of each subject becomes available to serve the community. Paulo (I) says he and Silvana started volunteer activities as a Math tutor for kids from Pitaguary village. According to Paulo, the idea came 
from the Movement's president who, by introducing him to Silvana, said "Paulo is a Math Wiz, he studies Mathematics at CEFET (Federal Center for Technological Education). It would be great if the two of you (Paulo and Silvana) got together to tutor these kids" (SP). Lotus Flower (FG) reports the change in her social space when she switches from the position of maid to that of user of Movement's activities, and collaborator in coordinating the self-esteem group and being a Movement coordinator

during the morning I cooked, cleaned the house, on Tuesday afternoon I would come to therapy and at night I would participate in the self-esteem group. On Thursdays I helped preparing the self-esteem group ... and then one day they came up to me and said "you are ready to be a coordinator." And then I said: "Yay!" right, because I've always wanted to learn more, so I accepted it. (Lotus Flower, FG)

The passage from volunteer work to being hired as Movement's paid employees is a concern for Movement's management due to people's financial need, and the situation of real poverty in the neighborhood. These initiatives promote a "strong" mental health service that, according to Rotelli (2001, p. 42) is "the service that does not choose, in any way, demands or conflicts, but on the contrary, elaborates dynamics and individualized response strategies that try to safeguard and enlarge the richness in people's lives, insane or sane." Therefore, they create a network of support where the subject with a history of suffering is not taken as object of intervention just receiving prescription medications and a roster of care activities.

Illness experience is taken into account as a positive aspect, because Movement understands that ill people can become a more qualified caregiver, with greater possibilities of welcoming, listening, and showing empathy. The experience in these new roles gives a new social space to insanity, in which the institutionalized resources potentiate the subjective resources, enabling the rupture of the care according to the traditional clinical paradigm.

\section{Biopolitical dimension}

By presenting itself as innovative, Movement reveals contradictions when capitalist logic is analyzed in its processes of subjectivation as a control society. This biopolitical dimension is described by Deleuze (2008) when he says that we are all part of a "control society" characterized by the overproduction capitalism where the individuals become samples, data, markets, or "banks," manipulated by marketing.

We analyze how these mechanisms of control take place in Movement, where they reveal themselves in daily practices, catches of an institutionalizing power. In 2006, Movement had a great enlargement of its activities, mainly after having an agreement with Fortaleza's City Hall, approved by the City Health Council, establishing a regular transfer of city funds for the Movement. 
So they could expand the mental health actions in the neighborhood and training courses for the workers in the city's public health network. In 1996, the Movement had two coordinators and 280 people were assisted in care practices for a more complex organization structure. In 2006, after the referred agreement, with 12 coordinators and a total of "500-1,000 people every week, as a result, 24,000-48,000 are assisted every year” (Godoy, Viana, Vasconcelos, \& Bonvini, 2012, p. 159).

That expansion provided more access to people who needed assistance, but also potentiated new possibilities of society control, with funders evaluating the continuity of the investment according to the achievement of goals, the amount of people assisted, and the elaboration of reports. Rute (FG) talks about these modifications: "before, we had more time to talk, to sit and if we had any complaints about someone, to talk about what we were feeling. Now, the Movement grew and we live on the run, with scheduled appointments and we don't have time." That means that demand for increase in productivity and enlargement of work spaces creates problems: "before, I think the people who participated in Movement were closer, I think there weren't classes (social). Now, I am under the impression that there is a certain division. I am a Doctor, I am a nurse so I won't hang out with anyone from the cleaning crew" (Jarbas, EF).

The Movement's president reports that a few problems happened with the arrival of professionals, appointed by the agreement with City Hall, which thought they were superior to the community members, establishing a vertical relation of knowledge/power. The substitution of these professionals was requested due to the following reason: "We need community professionals, not people who think themselves superior for having gone to college, that learned a lot of things and thought they are better than the health agents. In the community (Bom Jardim) people are used to seeing doctors that treat them like siblings" (Movement's President, I).

It is crucial to realize the contradictions of the Movement are challenges of maintaining the safekeeping and the closeness between people. Likewise, the Movement has to submit high productivity to justify its financiers. We comprehend care generates strengthening as something alive, permeated with emotions, fears, and conflicts. This is able to overcome the rigidity of rules and prescriptive rules. Hardt and Negri (2001) remind us that no matter how much you want to escape control, we are dominated by an Empire, in a new order dictated by the world capitalism's market, which is not based in territorial frontiers, causing great oppressing and destructing powers. However, at the same time that the Empire dominates, it also maintains liberation forces, in which the biopower is capable of strengthening lives. A life that sprouts out of situations of oppression, when a crowd performs a re-appropriation of the primary means of biopolitical production, meaning "having free access to, and control of, knowledge, information, 
communication and affection-appropriation of the language senses" (Hardt \& Negri, 2001, p. 430). This power of the crowd resides in becoming open to the possible, non-massified, and capable of creative and singular activities.

\section{Final considerations}

Many articles highlight the difficulty faced by mental health services in developing care practices that promote people's health and autonomy, stimulating very little organization that is more independent from the users and their families, once that place is still led, in most cases, by the service's workers (Almeida, Dimenstein, \& Severo, 2010; Figueiró \& Dimenstein, 2010; Vasconcelos, 2009). In Bom Jardin community mental health service in which the care practices were evaluated, we recognize a difference by the multiplicity of actions in the community space, focusing the richness in people's lives and their connections, developing the subjects' potential.

Considering that mental health care practices enable processes of strengthening (Montero, 2003), there cannot be a subject's existence outside the community sense. The care is not limited in theories or in activities, but claims the respect to the existential territory as support to express pain, discontent, the possibility of being and wishing for different things, of breaking away from a submission and resignation ideology (Goís, 2008).

Evaluating mental health service's care practices in the perspective of fortification of the people with a history of suffering, we seek to promote, in the mental health services, a care that is constituted by a network of meetings, beyond the assistance techniques. Then, these services are capable of admitting different movements mediated by pleasure and by the subjects' needs, permeated by a problematizing and loving dialog that favors the autonomy and liberation of each subject, potentiating the disruption from the circle of authority relations in the production of care, and developing therapeutic projects that do not lose their ethical and community dimension.

\section{References}

Almeida, K. S., Dimenstein, M., \& Severo, A. K. (2010). Empoderamento e Atenção Psicossocial: Notas sobre uma associação de saúde mental [Empowerment and psychosocial care: Notes on mental health association]. Interface-Comunicação, Saúde, Educação, 14 (34), 577-589. doi:10.1590/s1414-32832010005000009

Amarante, P. (1994). Psiquiatria Social e Reforma Psiquiátrica. [Social psychiatry and psychiatric reform]. Rio de Janeiro, Brazil: Fiocruz.

Amarante, P. (2003). A Clínica e a Reforma Psiquiátrica. [The clinic and the psychiatric reform]. In P. Amarante (Ed.), Archivos de Saúde Mental e Atenção Psicossocial (pp. 45-66). Rio de Janeiro, Brazil: Nau editora. 
Ayres, J. R. C. M. (2004). O cuidado, os modos de ser (do) humano e as práticas de saúde [The care, ways of being (of human being) and health practices]. Saúde e Sociedade, 13 (3), 16-29.

Basaglia, F. (2005). Escritos selecionados em saúde mental e reforma psiquiátrica. [Selected writings in mental health and psychiatric reform]. Rio de Janeiro, Brazil: Garamond Universitária.

Bosi, M. L. M., Carvalho, L. B., Sobreira, M. A. A., Ximenes, V. M., Liberato, M. T. C., \& Godoy, M. G. C. (2011). Inovação em saúde mental: Subsídios à construção de práticas inovadoras e modelos avaliativos multidimensionais. [Innovation in mental health: Subsidies for construction of innovative practices and multidimensional evaluation models]. Physis: Revista de Saúde Coletiva, 21(4), 1231-1252. doi:10.1590/s0103-73312011000400004

Bosi, M. L. M., \& Mercado, F. J. (2007). Pesquisa qualitativa de serviços de saúde. [Qualitative research in health services]. Petrópolis, Brazil: Vozes.

Carvalho, M. A. A. S., Ximenes, V. M., \& Bosi, M. L. M. (2012). Processos de fortalecimento em um movimento comunitário de saúde mental no nordeste do Brasil: Novos espaços para a loucura. [Strengthening processes in a community mental health movement in Northeast Brazil: New spaces for madness]. Aletheia, 37(2), 162-176.

Deleuze, G. (2008). Conversações. [Conversations]. São Paulo, Brazil: Editora 34.

Figueiró, R. A., \& Dimenstein, M. (2010). O cotidiano de usuários de CAPS: Empoderamento ou captura? [The daily life of CAPS's users: Empowerment or catches?]. Fractal Revista de Psicologia, 22(2), 431-446. doi:10.1590/s1984-02922010000800015

Franco, T. B., Merhy, E. E., Andrade, C. S., \& Ferreira, V. S. C. (2009). A produção subjetiva da Estratégia Saúde da Família. In T. B. Franco, C. S. Andrade, \& V. S. C. Ferreira (Eds.), A produção Subjetiva do Cuidado: Cartografias da Estratégia Saúde da Família. [The subjective production of the care: Cartographies of the family health strategy] (pp. 19-44). São Paulo, Brazil: Hucitec.

Godoy, M. G. C., Viana, A. P. F., Vasconcelos, K. A. G., \& Bonvini, O. (2012). O compartilhamento do cuidado em saúde mental: Uma experiência de cogestão de um centro de atenção psicossocial em Fortaleza-CE apoiada em abordagens psicossociais. [The sharing of mental health care: An experience of co-management of a psychosocial care center in Fortaleza supported psychosocial approaches]. Saúde e Sociedade, 21(1), 152-163. doi:10.1590/s0104-12902012000500013

Góis, C. W. L. (1993). Noções de psicologia comunitária. [Notions of community psychology]. Fortaleza, Brazil: Viver.

Góis, C. W. L. (2008). Saúde comunitária. [Community health]. São Paulo, Brazil: 440 Hucitec. Hardt, M., \& Negri, A. (2001). Império. [Empire]. Rio de Janeiro, Brazil: Record.

Martín-Baró, I. (1998). Psicología de la Liberación. [Liberation's psychology]. Madrid, Spain: Trotta.

Mecca, R. C., \& Castro, E. D. (2008). Experiência estética e cotidiano institucional: Novos mapas para subjetivar espaços destinados à saúde mental. [Esthetic experience and institutional daily life: New maps for subjectivating spaces for mental health]. InterfaceComunicação, Saúde, Educação, 12(25), 377-386. doi:10.1590/s1414-32832008000200012

Montero, M. (2003). Teoría e práctica de la psicología comunitaria: La tensión entre comunidad $y$ sociedad. [Theory and practice of community psychology: The tensión between community and society]. Buenos Aires, Argentina: Paidós.

Neiva-Silva, L. (2003). Expectativas futuras de adolescentes em situação de rua: Um estudo autofotográfico. [Future expectations of adolescents living on the streets: A self-photographic study] (Dissertation of Master). Postgraduate Program in Developmental Psychology. Federal University of Rio Grande do Sul, Porto Alegre, Brazil. 
Rotelli, F. (2001). Desinstitucionalização: Uma outra via. [Deinstitutionalization: Another path]. In F. Rotelli O. Leonardis, \& D. Mauri (Eds.), Desinstitucionalização (pp. 17-59). São Paulo, Brazil: Hucitec.

Vasconcelos, E. M. (2009). Perfil das organizações de usuários e familiares no Brasil, seus desafios e propostas. [Profile of users and family organizations in Brazil, its challenges and proposals]. Cadernos Brasileiros de Saúde Mental, 1(1), 29-42. 